\title{
15 \\ Combined Modeling of a Flume-Gravel-Trench System and Surrounding Unsaturated Soils
}

\author{
Joerg Schaffner and Manfred W. Ostrowski
}

Ongoing and intensive land development over several decades has led to increasing imperviousness of urban areas. This is particularly true for town and city centres. Precipitation cannot infiltrate into the ground and this reduces groundwater renewal. Instead, stormwater is conveyed by separate and combined sewer systems to the next treatment plant or receiving water.

Frequently, problems occur when further development is planned in suburban areas to be connected to the main sewer system. According to traditional technology, existing parts of the sewer system become overloaded and must be replaced by larger diameter sewers to convey additional sewerage and storm water.

In some cases some existing treatment plants become overloaded and must be rebuilt or modified to fulfil existing water quality standards. Investment costs for these modifications and extensions of the drainage system are distributed among the users connected to the system.

Internationally a broad consensus exists that the re-routing of stormwater back into the natural water cycle is compulsory from the ecological and economical point of view. It is well known that onsite infiltration of stormwater can contribute to considerably reducing stormwater peaks and volumes. Several infiltration technologies have been developed for this purpose, such as drainage wells, gravel trenches and pervious pipes that include subsurface storage, as well as depression and reservoir infiltration including surface storage. The BIRCO Company in Baden-Baden has developed a new drainage

\footnotetext{
Schaffner, J. and M. Ostrowski. 2002. "Combined Modeling of a Flume-Gravel-Trench System and Surrounding Unsaturated Soils." Journal of Water Management Modeling R208-15. doi: 10.14796/JWMM.R208-15.

(C) CHI 2002 www.chijournal.org ISSN: 2292-6062 (Formerly in Best modeling practices for Urban Water Systems. ISBN: 0-9683681-6-6)
} 
system for such situations to infiltrate less or least-polluted stormwater. It is a combination of a surface collector flume cut into the impervious area connected to a subsurface gravel filled infiltration trench.

By means of this infiltration system it is possible to disconnect impervious sub areas from the main sewer system independent of surface cover. It can be effectively applied in those cases where an impervious soil cover is compulsory for architectural and technical reasons or when ditch trench systems cannot be applied due to space limitations (Geiger and Dreiseitl, 1995).

The following fields of application can be emphasised:

- impervious yards of single family or semi-detached houses,

- roof runoff,

- drainage of sidewalks and bicycle lanes,

- school yards and other public less polluted areas,

- pedestrian zones, and

- parking areas with low or medium traffic frequencies in domestic or small to medium size industrial areas.

\subsection{Background}

\subsubsection{Introduction}

The first objective of this study was to develop design rules for the flumegravel-trench system as a function of the connected area and the dominant soil. Similar to the safety standard for a combined sewer system the flume-graveltrench system should be laid out for a five year return period. This task was done with the pollution load model SMUSI (Mehler and Leichtfuss, 1997) developed at the Institute of Hydraulic and Water Resources Engineering, Darmstadt University of Technology.

In the second stage the aim was to investigate the movement of the infiltrated water in the unsaturated soil. Therefore, it was necessary to create different scenarios with variable boundary conditions. The flume-gravel-trench system was located between buildings with variable distances to the system, soils and sizes of connected impervious areas. The calculations were done with the model Hydrus - 2D (Simunek et al., 1994) to assess the possible risk of wetting the basements of buildings close to the flume-gravel-trench system.

\subsubsection{Description of the Flume-Gravel-Trench System}

\section{Structure and mode of operation}

The infiltration gutter consists of two horizontal U-shaped concrete channels as shown in Figure 15.1. 




Figure 15.1 Cross-section A-A.

The upper channel, the collector flume, is covered with a heavy duty, water-permeable metal cover. Thus it can also be used in a parking lot. A concrete support beside the collector flume prevents it from floating and distributes the forces from a possible load. Two small hooks on the collector flume are used as an anchorage for the concrete. The collector flume and the trench tunnel have identical profiles to reduce production costs.

The water collected by the flume passes a collecting and cleaning device before entering the lower distribution flume. The flumes as well as the supporting concrete rest on a trench filled with gravel of $8 / 32$ diameter. This gravel trench is called a rigole.

The rigole is surrounded by a protecting textile to prevent finer particle size distributed soil from entering the gravel layer. Between the trench tunnel and the rigole, a metal sieve prevents coarse pollutants entering subsoils. A plan view of a possible application is shown in Figure 15.2.

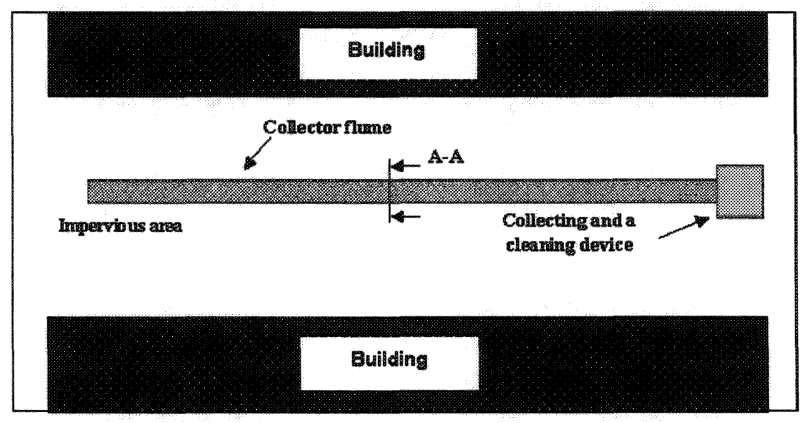

Figure 15.2 Example application of the flume-gravel-trench system. 
Runoff from sealed surfaces is accumulated in the collector flume. From the collector flume, water flows into the collecting and cleaning slot, where dirt particles are filtered. The water calms down now and runs controlled into the trench tunnel. Then the water is delivered by the trench tunnel into the rigole and infiltrates from there into the unsaturated soil.

\subsubsection{Approach}

The investigation was divided into two interrelated work phases.

The first phase covers the derivation of design parameters for the flume -gravel-trench system being the cross section and volume of the rigole. They depend on local precipitation, on sealed surface area connected and on permeability of subsoil. The calculations were done with the pollution load model SMUSI 4.0. The system was loaded with a continuous precipitation time series of 30 years (long-term simulation). The parameters directly-connected surface area and permeability of the prevailing soil were varied in the calculations. In the model SMUSI, the parameters cross-section and volume of the rigole were determined iteratively in such a way that the selected failure frequency is achieved.

In the second phase, the development of critical capillary fringe of the groundwater became relevant due to longer precipitation periods with high successive daily totals of precipitation in the simulation. For these periods the storage and transport processes were examined using the finite element model HYDRUS-2D (Simuneket al., 1994). The behaviour of the unsaturated soil zone below the rigole should be viewed under variable structural boundary conditions. Therefore it was not possible to develop a unique calculation rule.Only the results of the selected scenarios became clear, e.g. overall predicates for the minimum distances from buildings to the infiltration systems.

\subsubsection{Description of the Initial Conditions for Both Models}

Soils

The flume-gravel-trench system is to be used in practice both for new and existingbuildings. Thus a large range of natural and disturbed soils (e.g. building debris) is possible. The target for the calculations with the models SMUSI and Hydrus 2-D was to prove which soils for the applications of the gutter system seem suitable and which not. Artificial layers were not investigated because it is very difficult to describe the hydraulic characteristics of such layers and to choose adequate parameters. The parameters of the chosen soils (Table 15.1) were taken according to Montenegro (1995). 
The following soils were investigated :

Table 15.1 Chosen soils (after Montenegro, 1995).

\begin{tabular}{cccc}
\hline Soil type & Hydraulic conductivity $[\mathrm{m} / \mathrm{s}]$ & $\theta_{8}[\mathrm{Vol} / \mathrm{Vol}]$ & $\theta_{\mathrm{r}}[\mathrm{Vol} / \mathrm{Vol}]$ \\
\hline Sand & $8.25 * 10-5$ & 0.43 & 0.045 \\
Loamy Sand & $4.05 * 10-5$ & 0.43 & 0.057 \\
Sandy loam & $1.23 * 10-5$ & 0.41 & 0.065 \\
Loam & $2.88 * 10-6$ & 0.43 & 0.078 \\
Clay & $5.55 * 10-7$ & 0.38 & 0.068 \\
\hline
\end{tabular}

$\theta$ water content $[\mathrm{Vol} / \mathrm{Vol}]$

$\theta_{\mathrm{r}}$ water content [Vol/Vol]

$\theta_{s}$ water content $[\mathrm{Vol} / \mathrm{Vol}]$

\subsection{Simulations with SMUSI 4.0}

\subsubsection{Modeling the Flume-Gravel-Trench System}

The modeling of the flume - gravel - trench system was done with the pollution load model SMUSI 4.0. SMUSI is a distributed deterministic-hydrologic precipitation discharge and material transport model. It is a continuous longterm simulation model. Besides flow, it calculates concentrations of water constituents such as COD, BOD and filterable solids, considered important for the evaluation of stormwater overflows on receiving waters, both in existing or planned systems.

The infiltration system is defined in SMUSI by three elements. These are two impervious areas and a storage basin, as commonly used in sewer systems. In Figure 15.3 the arrangement of the system elements is shown.

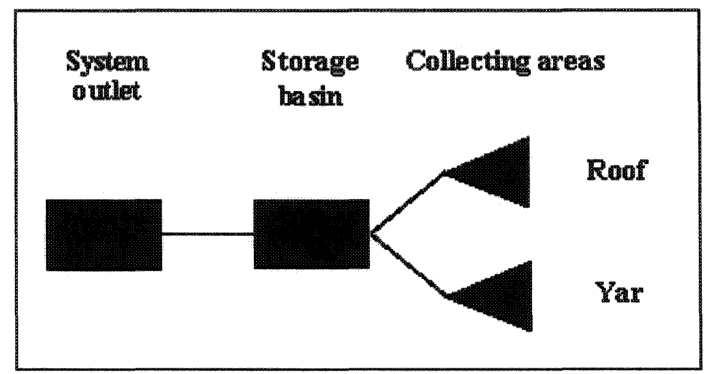

Figure 15.3 Modeling the flume-gravel-trench system with SMUSI 4.0. 
The sealed areas represent roof and yard areas respectively connected to the flume. These surfaces can be loaded either with a model rain series or a historical rain event. The storage element represents the complete flume-graveltrench system. It is defined by the parameters type of basin, basin volume and throttle discharge. The basin volume covers the volume of the upper and lower channel, the collecting and cleaning slot as well as that of the gravel trench. The throttle discharge is determined by the infiltration performance of the gravel trench into the prevailing soil.

If the supply of rainwater exceeds the maximum infiltration capacity of the prevailing soil the gravel trench is flooded. As soon as the maximum volume of the rigole is exceeded, the arriving water accumulates in the trench tunnel, the collecting and cleaning device, as well as in the collector flume. The maximum volume of the storage basin B100 is reached when the collector flume and all other parts of the flume-gravel-trench system are surcharged. Then the parking lot surface is assumed to be flooded. After the end of the rain event or after the end of the maximum drainage activity of the attached sealed surfaces, the rigole will infiltrate the rain water with maximum performance into the prevailing soil. The flooded sealed surfaces will fall dry when all rainwater passes the flumegravel-trench system.

\subsubsection{Determination of the Basin Volumes}

The volume of the storage basin is obtained from the total of the volumes of the collector flume plus trench tunnel(VFlumes), the collecting and cleaning device $\left(\mathrm{V}_{\mathrm{CCD}}\right)$ as well as the gravel trench $\left(\mathrm{V}_{\mathrm{GT}}\right)$.

$$
V_{\text {Total }}=V_{\text {Flumes }}+V_{C C D}+V_{G T} \quad\left(\mathrm{~m}^{2}\right)
$$

The maximum specifications were fixed by the Birco company. The collector flume and the trench tunnel should have a fixed height and width of $0.15 \mathrm{~m}$ with a length of $6 \mathrm{~m}$. The collecting and cleaning slot should have constant dimensions of $1 \mathrm{~m}$ height, $0.4 \mathrm{~m}$ width and $1 \mathrm{~m}$ length. The dimensions of the rigole and thus the volume should be varied in the calculations with the upper limit of width or height of $1 \mathrm{~m}$ and a maximum length of $14 \mathrm{~m}$.

In order to create an arranged base for comparative calculations between the soils, different volumes for the modeling had to be defined. The target was to increase the dimensions of the rigole in such a way that the volume and the infiltration surface of the rigole rises constantly.

The effective infiltration surface of the rigole was calculated following ATV A-138 (ATV - Regelverk, 1990). The bottom surface area of the rigole is calculated with $100 \%$, the front, back and side surfaces are calculated in each 
case with $50 \%$ of the effective infiltration surface. Thus the following equation results:

where:

$$
A_{V}=B^{*} L+H^{*} L+H^{*} B \quad\left(\mathrm{~m}^{2}\right)
$$

$$
\begin{aligned}
B & =\text { width }(\mathrm{m}) \\
L & =\text { length }(\mathrm{m}) \\
H & =\text { height }(\mathrm{m})
\end{aligned}
$$

The gravel compartment has a depth a height of $500 \mathrm{~mm}$ for volume no.1, a width of $600 \mathrm{~mm}$ and a length of $6000 \mathrm{~mm}$. These dimensions increase up to the volume no. 13 with a depth and width of $1 \mathrm{~m}$ and a length of $14 \mathrm{~m}$. The development of infiltration surface and storage volume according to the volume no. can be seen in Figure 15.4.

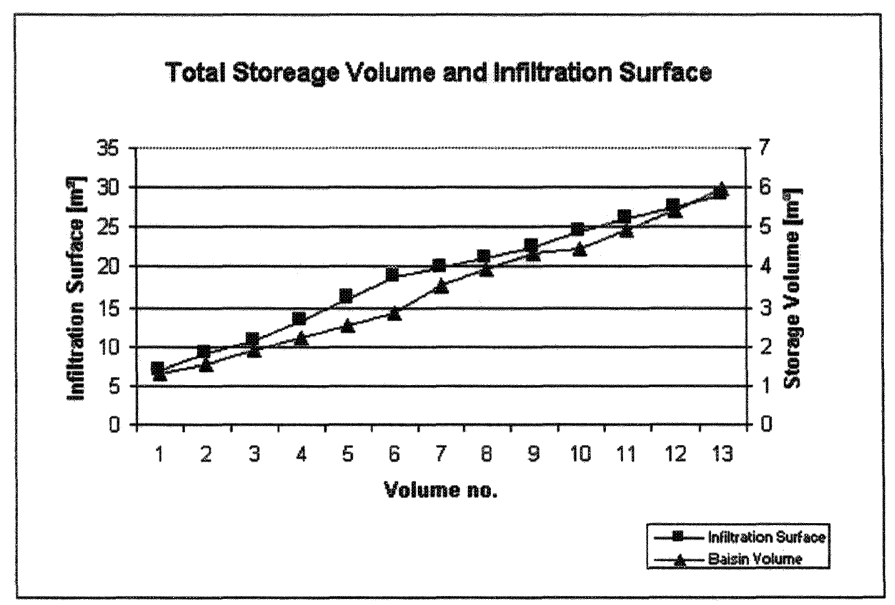

Figure 15.4 Investigation of total storage volume and infiltration surface.

The possible infiltration rate of the rigole always depends on the surrounding soil and its unsaturated hydraulic conductivity. The infiltration rate according to German standards ATV A-138 is determined according to the equation:

where:

$$
q_{s}=v_{f, u} * A_{s, w}
$$

$$
\begin{aligned}
A_{S, W} & =\text { infiltration area }\left(\mathrm{m}^{2}\right), \text { and } \\
v_{f, u} & =\text { mean filter velocity }(\mathrm{m} / \mathrm{s})
\end{aligned}
$$




\subsubsection{Simulating the Flume-Gravel-Trench System with Continuous Rainseries}

SMUSI offers the possibility of using long-term observed precipitation series for continuous long term simulations of canalised areas or the external areas. The 30-year rain series used here originates from the station Essen Steele in Western Germany. It covers the years 1952-1981 in 5 minute steps. The middle annual precipitation depth is approximately $804 \mathrm{~mm} / \mathrm{y}$, which is representative for larger parts of Germany.

\subsubsection{Determination of the System Volume for Varying Impervious Area}

The objective of the calculations with SMUSI was the development of a design rule for the size of the gravel trench as a function of the surrounding soil type, as well as the impervious area. For a given size of the connected area and the soil conditions, the flume-gravel-trench system should not be surcharged more then once in five years. In this context a preliminary investigation for each soil type was carried out to find the required volume of the rigole so that the required failure frequency would not be exceeded. This was achieved for sand with volume no. 7, for loamy sand with volume no. 8 and for sandy loam with volume no. 13. Loam and clay could not satisfy the failure frequency chosen even for volume no. 13.

With these initial values the sizing of the gravel trench began. First the geometry of the rigole was changed by trial and error not to exceed one overloading in five years with a sealed surface of $250 \mathrm{~m}^{2}$. As soon as this was achieved, the attached surface was extended stepwise by $50 \mathrm{~m}^{2}$. Now the width, length and height of the rigole were increased iteratively in such a way that the desired number of overloading was reached again. The calculations were finished when it was not further possible to reach the design standard with the maximum dimensions of the rigole.

For sand, the attached surface could be expanded up to a maximum of $450 \mathrm{~m}^{2}$. Loamy sand can satisfy the overloading frequency with an attached surface of $350 \mathrm{~m}^{2}$. Sandy loam could cope only with the maximum measurements of the rigole the required number of overloading for an attached surface of $250 \mathrm{~m}$.

An analysis of the results showed that the gravel trench volume, the infiltration surface and the infiltration rate were a function of the attached sealed surface regarding the required failure frequency (Figures 15.5, 15.6 and 15.7). Linear regressive functions for gravel trench volume, infiltration surface and infiltration rate could be created in each case for sand and loamy sand. These 
functions do almost cover the actual result curves. Under a prerequisite of the respective hydraulic conductivity for sand and loamy sand these functions can be considered as a first estimate. If the hydraulic conductivity measured in practice should deviate significantly from the ones assumed, the functions can not be used for design. Further investigations will show what differences must be expected for deviating hydraulic conductivity.



Figure 15.5 Basin volume as a function of the connected sealed surface

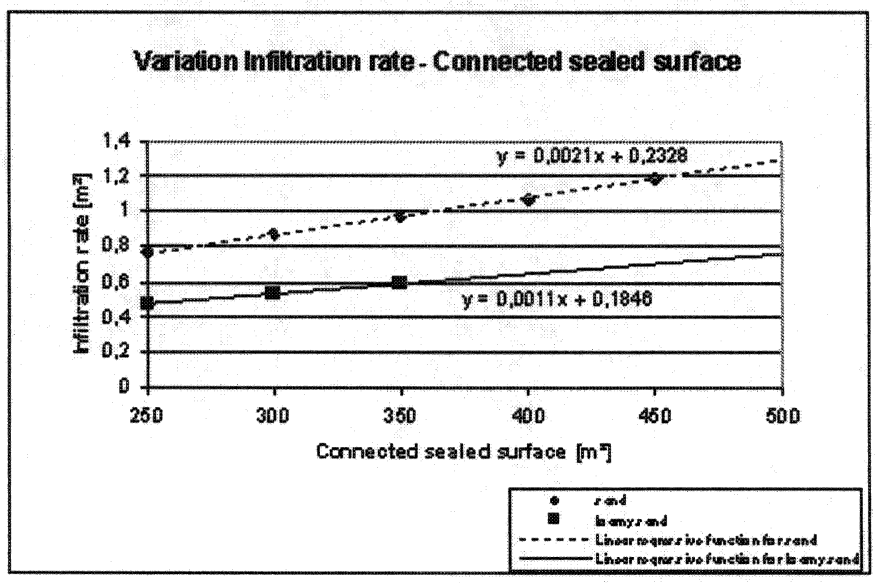

Figure 15.6 Infiltration rate as a function of the connected sealed surface. 


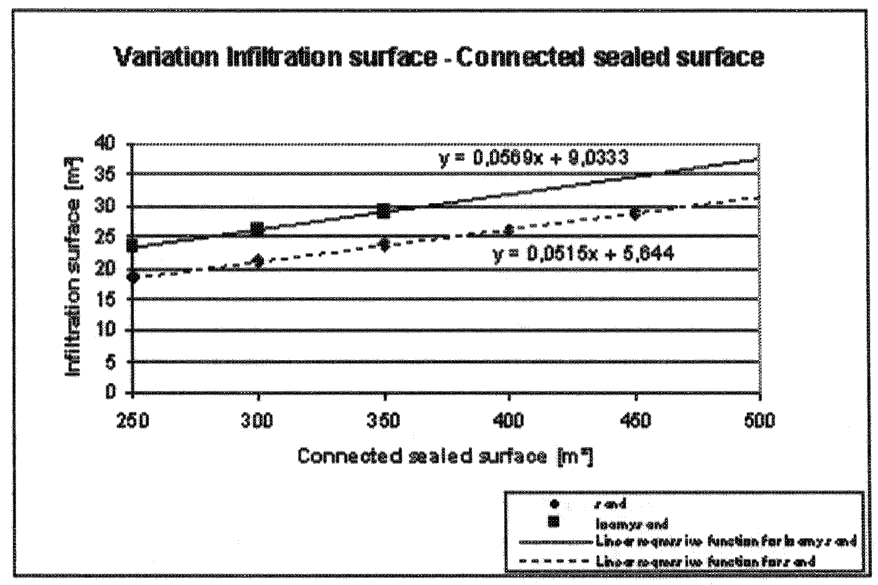

Figure 15.7 Infiltration surface of the rigole as a function of the connected sealed surface.

Design rule for sand with $k_{f}=8.25 * 10^{-5}(\mathrm{~m} / \mathrm{s})$

Storage volume:

Infiltration rate:

Infiltration surface:

where:

$$
\begin{aligned}
& V=0.014 \cdot A_{K}-0.267 \quad\left(\mathrm{~m}^{3}\right) \\
& q=0.0021 \cdot A_{K}+0.2328 \quad(1 / \mathrm{s}) \\
& \begin{aligned}
q & =0.0021 \cdot A_{K}+0.2328 \quad\left(\mathrm{~m}^{2}\right) \\
A_{V} & =0.0515 \cdot A_{K}+5.644 \quad
\end{aligned}
\end{aligned}
$$

$$
A_{K}=\text { connected sealed surface }\left(\mathrm{m}^{2}\right)
$$

Design rule for loamy sand with $k_{f}=4.05^{*} 10^{-5}(\mathrm{~m} / \mathrm{s})$

Storage volume: Infiltration rate: Infiltration surface:

$$
\begin{aligned}
& \left(\mathrm{m}^{3}\right) \\
& V=0.0147 \cdot A_{K}+0.87 \quad(1 / \mathrm{s}) \\
& q=., 0011 \cdot A_{K}+0.1846 \quad\left(\mathrm{~m}^{2}\right)
\end{aligned}
$$

\subsection{Calculations with Hydrus 2-D}

\subsubsection{Description of the Model}

Hydrus 2-D is a two-dimensional physically-based soil model for the calculation of flow and pollutant transport in the saturated and unsaturated soil zone. It is based on the Darcy Richards equation for the seepage flow and the convective dispersion equation, which both are solved numerically. The model considers 
capillary rise by plant roots in the unsaturated soil zone. It can consider irregular boundaries, whereby special attention is given to inflow and the pressure head. Systems can consist of several layers of soil with local anisotrophy structures. Flow and transport can be calculated in vertical, horizontal and vertically axes. Boundaries can have constant or variable inflow or pressure head.

\subsubsection{Modeling the Unsaturated Soil Zone}

The system geometry is given in Figure 15.8. Boundary conditions, i.e. inflow into the gravel trench, were taken from the continuous long term SMUSI simulations.

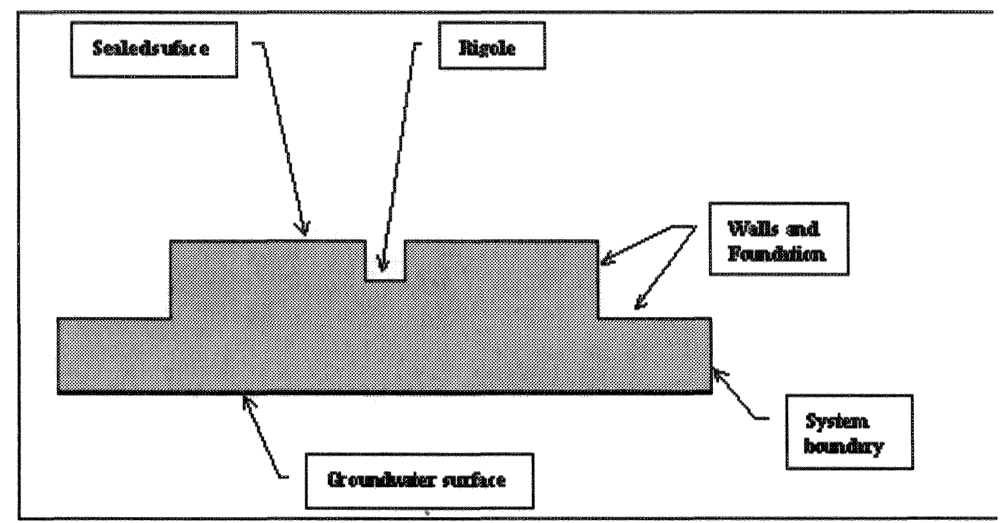

Figure 15.8 Model geometry.

The water which passed the collector flume and the trench tunnel infiltrates via the gravel trench (rigole) into the soil. Ground surface, building walls and the lower boundaries were defined as impermeable boundaries. The surfaces of the gravel trench were illustrated with constant or variable flow depending on the purpose of the simulation. The groundwater surface was defined as a boundary with a constant free surface ( $0 \mathrm{~m}$ water column).

The calculations were executed in each case for sand, loamy sand and sandy loam with the parameters specified in Table 15.1. In two individual scenarios the flow of the infiltrated water into the soil was analysed with different initial conditions.

\subsubsection{Scenario 1}

The basis of this investigation was the geometry represented in Figure 15.9. It was assumed that the distance between adjacent walls were $7 \mathrm{~m}$. The flumegravel-trench system was placed exactly in the center between them. The 
distance of the groundwater surface to the rigole was assumed to be $2 \mathrm{~m}$. The foundations of the houses were assumed to be $1 \mathrm{~m}$ above the groundwater surface. The sealed surface attached to the system amounted to $250 \mathrm{~m}^{2}$.

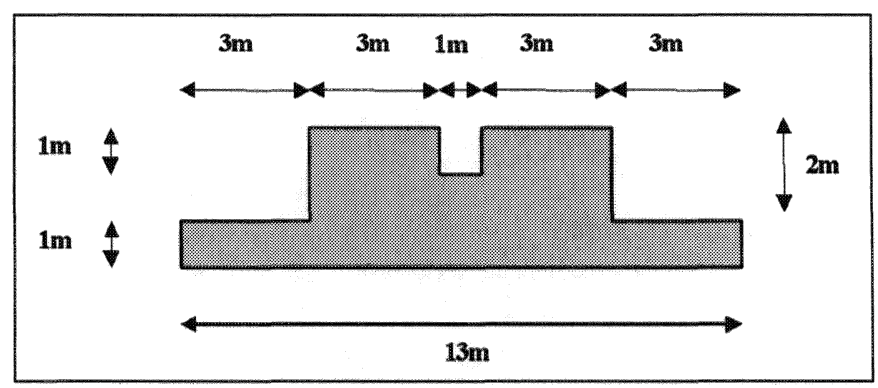

Figure 15.9 Selected dimensions.

\subsubsection{Simulation of One Month with Time-varying Infiltration Rate and Resulting 5 year Overloading Event}

In these simulation runs the coincidence of most unfavourable circumstances was assumed. First inflow time series were produced with SMUSI for the wettest monthly historical record, leading to highly saturated sub surface soil conditions. In addition to these unfavourable initial conditions the design storm was added to find out how close the seeping water moves to the walls and thus could represent a possible danger for the buildings.

The analysis of the results showed that with sand (Figure 15.10) and loamy sand (Figure 15.11) no problems are to be expected concerning a possible wetting of the walls. With sandy loam (Figure 15.12) there is a strong rise of the water table in the soil under the house foundations, up to $50 \%$ of saturation. For an additional increase of the ground-water level plus the

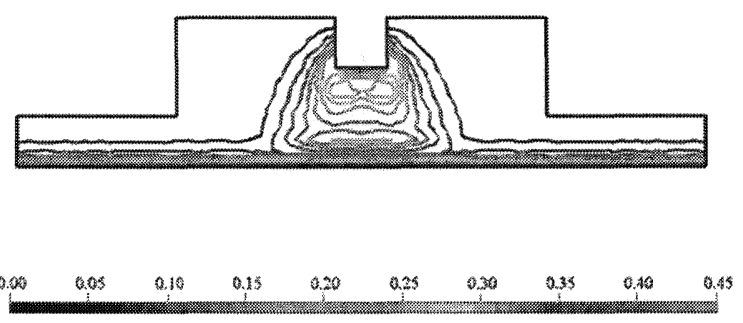

Figure 15.10 Water content of the sand. 
mentioned rain event this could lead to a dangerous situation for the basements. If the seeping rain water is not rapidly drained the infiltrated water can affect the walls of the buildings. Therefore a larger distance of the foundation to the ground-water level is strongly recommended for this case.
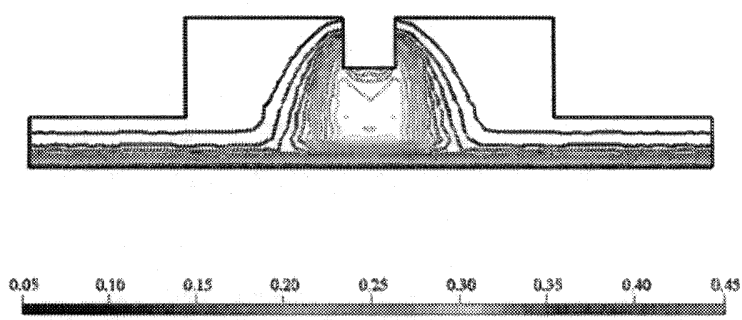

Figure 15.11 Water content loamy sand.
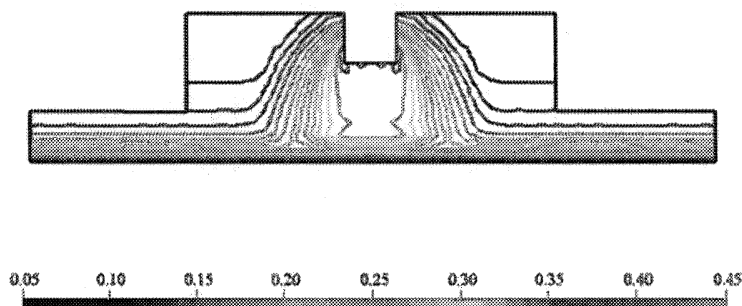

Figure 15.12 Water content sandy loam.

\subsubsection{Scenario 2}

In this scenario the directly-connected surface to the flume-gravel-trench system was gradually increased to study the effects on the prevailing soil, based on the geometry of scenario 1 . Starting from $250 \mathrm{~m}^{2}$ the area was increased stepwise by $50 \mathrm{~m}^{2}$.

For this calculation the system was loaded with a constant infiltration rate for ten days. The infiltration rate per attached surface resulted from the SMUSI calculations accounting for the required failure frequency

The results indicated that an increase of the attached sealed surface of this magnitude is insignificant for the propagation of water seepage into the soil. The potential for $250 \mathrm{~m}^{2}$ attached surface in the case of sand (Figures 15.13,15.14) hardly differs from an attached surface of $450 \mathrm{~m}^{2}$. Loamy sand also showed no significant differences. It was possible to increase the size of the attached surface for sandy loam without exceeding the failure frequency, according to SMUSI. 

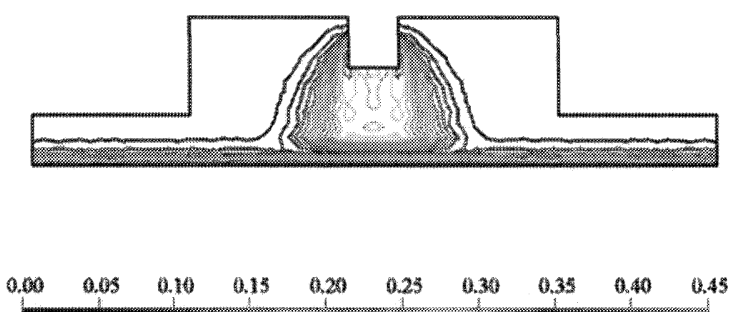

Figure 15.13 Sand, $250 \mathrm{~m}^{2}$ attached surface.

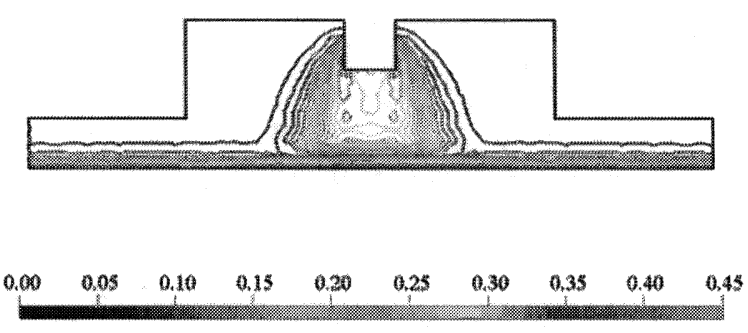

Figure 15.14 Sand, $450 \mathrm{~m}^{2}$ attached surface

\subsection{Summary}

The first part of this chapter dealt with the design of the geometric sizes for the flume-gravel-trench system as a function of the local soils as well as the attached sealed surface. With the aid of pollution load simulation model SMUSI 4.0 linear design rules for the sizing of the flume-gravel-trench system were derived.

For a preliminary investigation for each soil the critical system volume was determined. It became clear that loam and clay as prevailing soils are not practical for the flume-gravel-trench system.

The second calculation was the sizing of the flume-gravel-trench system with a variation of the directly-connected sealed surface. The results of the calculation showed that sand can infiltrate the flow from a surface of $450 \mathrm{~m}^{2}$, and satisfies the required overloading frequency when the maximum sizes of the flume-gravel-trench system were chosen. Loamy sand does not exceed the surcharge frequency with a maximum $350 \mathrm{~m}^{2}$ of attached surface, provided the maximal storage volumes of the flume-gravel-trench system is given. With sandy loam it was only possible to connect a surface of $250 \mathrm{~m}^{2}$ when choosing the largest dimensions of the gravel trench. 
These results made it possible to derive design rules which must be regarded with care, since they very strongly depend on the hydraulic conductivity of the soil.

The second part of this chapter deals with the storage and transport processes in the unsaturated soil zone within and below the gravel trench. With the help of the finite element model Hydrus 2-D the movement of the water, infiltrated from the gravel trench into the soil, was illustrated.

The behaviour of the unsaturated soil zone was analysed for two different scenarios. In scenario 1 the movement of the seeping water between two houses with varying distances was considered. It became clear that in the case of sandy loam a strong rise of the water content in the soil occurs. Near the walls it increased up to $50 \%$ of saturation. In this case the flume-gravel-trench system cannot be recommended.

In scenario 2 the attached sealed surface for all soils was increased. The results of the calculations showed that for sand and loamy sand the increase of the attached surface is insignificant for the propagation of the seeping water in the soil under the flume-gravel-trench system.

Finally it can be said that with the dimensions chosen for the scenario 1 only a peak load event leads to a precarious rise of the water content in the sandy loam. It also became clear that this high water content lasts only for a short time.

Hydrus 2-D showed that the distance between the walls and the gravel trench should not fall below $3 \mathrm{~m}$. Otherwise a high water content in the soil beneath the walls can lead to serious problems for basements. The distance of the groundwater surface to the house foundation should be more than one meter to make sure that the zones with a high water content caused by the flumegravel-trench system do not reach the basements and the possible fluctuations of the groundwater level does not affect them.

The combination of both models, SMUSI and HYDRUS, showed that it is difficult to run these two models with varying parameters. Without any interface between the models it is very time consuming to run many calculations successfully. It isdifficult to convert the data from SMUSI for use in HYDRUS. Further work needs to be done to create an interface that allows to transfer the results of SMUSI directly into HYDRUS as boundary conditions.

\section{References}

ATV-Regelwerk A-138 (1990): Bau und Bemessung von Anlagen zur dezentralen Versickerung von nicht schädlich verunreinigtem Niederschlagswasser, Gesellschaft zur Förderung der Abwassertechnik e.V., St. Augustin. 
Geiger, W., Dreiseitl, H. (1995): Neue Wege für das Regenwasser, Handbuch zum Rückhalt und zur Versickerung von Regenwasser in Baugebieten, Hrsg. Emschergenossenschaft, Essen und Internationale Baustellung Emscher Park $\mathrm{GmbH}$, Gelsenkirchen, Oldenburg Verlag $\mathrm{GmbH}$, München.

Mehler, R., Leichtfuss, A. (1997): Dokumentation des Schmutzfrachtsimulationsmodells SMUSI, Version 4.0, Hrsg. Institut für Wasserbau und Wasserwirtschaft der TU Darmstadt, Fachgebiet Ingenieurhydrologie und Wasserbewirtschaftung, Darmstadt.

Montenegro Ferrigno, H. (1995): Parameterbestimmung und Modellierung der Wasserbewegung in heterogenen Böden, Fortschritt-Berichte VDI, Reihe 15 Umwelttechnik, Nr. 134, VDI-Verlag, Düsseldorf.

Simunek, J., Vogel, T., Van Genuchten, M.TH. (1994): The SWMS_2D Code for Simulating Water Flow and Solute Transport in Two-Dimensional Variably Saturated Media, Version 1.21, U.S. Salinity Laboratory Agricultural Research Service, U.S. Department of Agriculture Riverside, California. 